\title{
Fast removal of concentrated heavy metal ions using an alginate-poly(ethylene imine) biological adsorbent
}

\author{
Zhuoliang Ye, a), Mi Tang, b) and Jingyi Song ${ }^{1, c)}$ \\ ${ }^{1}$ School of Chemical Engineering, Fuzhou University, Fuzhou, Fujian 350116, P. R. China. \\ a)ye_zhuoliang@163.com \\ b)1226115591@qq.com \\ c)jingyiddf@vip.qq.com
}

\begin{abstract}
Accumulation of heavy metals in aqueous environment has raised increasing concerns for public health. An alginate based biodegradable adsorbent was successfully developed for fast removal of heavy metals, and could adsorb 99.4\% Cu(II) in 10 min when immersed in $10 \mathrm{mM} \mathrm{Cu(II).} \mathrm{Surface} \mathrm{characteristics}$ exhibited $25.65 \mathrm{wt} \%$ occupancy of $\mathrm{Cu}(\mathrm{II})$, further demonstrating the high adsorption capacity of the adsorbent. The adsorbent can be regenerated using either $10 \mathrm{wt} \%$ of $\mathrm{Na}_{2} \mathrm{CO}_{3}$ or $0.1 \mathrm{M}$ HCl. Reusability under each condition did not show decrease. Adsorption of Fe(II) was also tested. The adsorbent showed 95\% removal of $\mathrm{Fe}(\mathrm{II})$ in just $2 \mathrm{~min}$. These results demonstrate successful design and preparation of a novel biodegradable adsorbent with a matrix of properties suitable for application in fast removal of heavily polluted waste water containing a high content of metal ions.
\end{abstract}

\section{INTRODUCTION}

Due to fast development of modern society, growing release of heavy metals has adversely impacted our aqueous environment. Accumulation of the heavy metals in food chain has raised increasing concerns for public health. Various methods, such as adsorption, ion-exchange, electrolysis and precipitation, have been applied to remove the heavy metals. Among these methods, adsorption has been suggested as a low cost solution. Biological material based adsorbent is bio-degradable and environmentally friendly, and therefore, advantageous over many other synthetic materials to reduce heavy metal pollution.

Alginate based biological adsorbent has been well studied for this application [1]. However, as it has been extensively reported, the alginate adsorbent is easy to disintegrate or dissolve during regeneration [2]. A method such as proper cross-linking is required if high stability of the adsorbent is demanded. Moreover, slow kinetics has further limited practical application of the adsorbent. Therefore, it is desirable to develop a kind of alginate adsorbent with fast adsorption kinetics and high stability so that the adsorbent can be reused after regeneration.

Poly(ethylene imine) (PEI) is a kind of polycationic polymer. It can form stable cross-linking with alginate, preventing the alginate structure from disintegration during regeneration process. Furthermore, the amino groups introduced by PEI can enhance adsorption via forming complexes with some metals. Therefore, an biological alginate based adsorbent was developed by crosslinking sodium alginate using PEI in this work. The adsorption kinetics was examined under a condition that contained a high concentration of $\mathrm{Cu}(\mathrm{II})$. Regenerating methods using either sodium carbonate or hydrogen chloride were compared and reusability of the adsorbent was further tested. The adsorption of Fe(II) ion was also examined.

\section{MATERIALS AND METHODS}

\section{Materials}

Sodium alginate, copper(II) chloride dihydrate, iron(II) sulfate heptahydrate, hydrogen chloride, sodium carbonate and sodium chloride were purchased from Sinopharm Chemical Reagent Co., Ltd. PEI (Mw 70, 000) was 
purchased from Sigma-Aldrich Co., Ltd.

\section{Preparation of the adsorbents}

Sodium alginate was dissolved in D.I. water and stirred at high speed with a magnetic stirrer to make $0.5 \mathrm{wt} \%$ homogeneous solution. The freshly prepared solution was subsequently freeze-dried to remove moisture. The resulting samples were first cross-linked with Copper(II) chloride dihydrate $(0.323 \mathrm{~g} / \mathrm{g}$ alginate) and then PEI (in mass ratios of about 1 PEI : 1 Copper(II) chloride dihydrate : 3 alginate). Samples were boiled for 30 minutes to speed up the cross-linking process.

\section{Regeneration}

For regeneration, either $0.1 \mathrm{M} \mathrm{HCl}$ ( $\mathrm{Li}$ et al., 2013) or $10 \mathrm{wt} \% \mathrm{Na}_{2} \mathrm{CO}_{3}$ solution was used. The adsorbent-ion complexes were immersed in $10 \mathrm{ml} \mathrm{HCl}$ or $\mathrm{Na}_{2} \mathrm{CO}_{3}$ solution and magnetically stirred. The regeneration process lasted 6 hour using $\mathrm{HCl}$ or 2 day using $\mathrm{Na}_{2} \mathrm{CO}_{3}$. After a certain period of time, aliquots of the solution were taken and centrifuged in micro-centrifuge for $1 \mathrm{~min}$. The supernatent was removed for assay of metal concentration using Flame Atomic Absorption Spectroscopy (FAAS). After regeneration, the adsorbent was washed to remove unsorbed metal. Finally, the adsorbent was obtained by centrifuge and depletion of the supernatent.

\section{Adsorption of heavy metal}

$10 \mathrm{~mL}$ of Copper(II) chloride dihydrate solution ( $10 \mathrm{mM})$ and adsorbent $(0.03 \mathrm{~g})$ were added to a $25 \mathrm{~mL}$ beaker and magnetically stirred for $10 \mathrm{~min} .0 .5 \mathrm{ml}$ samples were taken out from the suspension every 2 min and centrifuged in micro-centrifuge for $1 \mathrm{~min}$. The supernatent was removed for assay of metal concentration (C) using FAAS. The adsorption capacity (q, mg/g alginate) was calculated using the mass balance equation: $\mathrm{q}=\left(\mathrm{C}_{0}-\mathrm{C}\right) * \mathrm{~V} * \mathrm{Mw} / \mathrm{m}$, where $\mathrm{C}_{0}$ is the initial concentration of the metal solution $(\mathrm{mM}), \mathrm{V}$ is the volume of solution $(\mathrm{L})$, $\mathrm{Mw}$ is the molecular weight of the metal ion and $\mathrm{m}$ is the amount of adsorbent (g).

\section{Elemental analysis of the adsorbent}

The elemental analysis of the adsorbent was performed after regeneration using $\mathrm{Na}_{2} \mathrm{CO}_{3}$ and re-adsorption of $\mathrm{Cu}(\mathrm{II})$ by a scanning electron microscope coupled with energy dispersive $\mathrm{X}$-ray analysis (SEM-EDAX) as reported elsewhere [3] using a Nova NanoSEM 230 system (FEI, USA). The system can be used to acquire quantitative spot analysis and qualitative or quantitative X-ray elemental maps.

\section{RESULTS AND DISCUSSION}

\section{Adsorption of copper(II) ion}

At a high loading of $\mathrm{Cu}(\mathrm{II})(\sim 10 \mathrm{mM})$, the alginate-PEI adsorbent exhibited fast adsorption kinetics, reducing the metal concentration down to $0.16 \mathrm{mM}$ after just $2 \mathrm{~min}$ (Fig. 1a). The percentage of metal removal was more than 98\% (Fig 1b). The adsorbent can further remove copper to an extent as high as $99.4 \%$ after 10 min, and reached a capacity of $202 \mathrm{mg} / \mathrm{g}$ alginate. In comparison, the adsorption rate by freeze-dried sodium alginate adsorbent was much slower, showing only $15.7 \%, 24.6 \%$ and $64.3 \%$ removal of $\mathrm{Cu}(\mathrm{II})$ after 2, 10 and 60 mins, respectively (Fig. 1b). It has been suggested that equilibrium adsorption of $\mathrm{Cu}(\mathrm{II})$ can be achieved within 60 min using an adsorbent via molecular imprint technique [4]. During our preparation, the target ion was also incorporated into the adsorbent, under which condition the adsorbent could form coordinated geometry for fast adsorption based on the charges and sizes of the target ion. Moreover, our adsorbent exhibited even faster adsorption than a nano-sized carbon immobilized alginate bead that can remove $80 \%-95 \%$ metal in 2 hour as reported elsewhere [5]. Therefore, the adsorbent here should be very useful to remove $\mathrm{Cu}$ from the concentrated waste water.

\section{Regeneration}

In order to examine the reusability of the adsorbent, two regenerating methods were explored. Fig. 2 shows that when the PEI-alginate adsorbent was regenerated using sodium carbonate, the adsorption capacity could reach 201 
$\mathrm{mg} / \mathrm{g}$ alginate, which is comparable to that from first run (202 $\mathrm{mg} / \mathrm{g}$ alginate). If the adsorbent was regenerated using $0.1 \mathrm{M}$ hydrogen chloride, it showed adsorption capacity of $4.6 \mathrm{mg} / \mathrm{g}$ alginate, which was $23 \%$ of that using sodium carbonate. The adsorption capacity did not reduce after a 2nd regeneration cycle, suggesting the adsorbent was reusable under either regenerating conditions (Fig. 2). As shown in Table 1, surface characteristics of the adsorbent demonstrated a high content of $\mathrm{Cu}(\mathrm{II})\left(25.65 \mathrm{Wt} \%\right.$ ) after regeneration using $\mathrm{Na}_{2} \mathrm{CO}_{3}$ and re-adsorption of $\mathrm{Cu}(\mathrm{II})$, confirming high capacity of the adsorbent for $\mathrm{Cu}(\mathrm{II})$ adsorption. Only $1.18 \mathrm{Wt} \% \mathrm{Cl}^{-}$was present on the surface, suggesting $\mathrm{Cu}(\mathrm{II})$ was in a complex with the adsorbent, probably via interaction with $\mathrm{COO}^{-}$group of alginate.
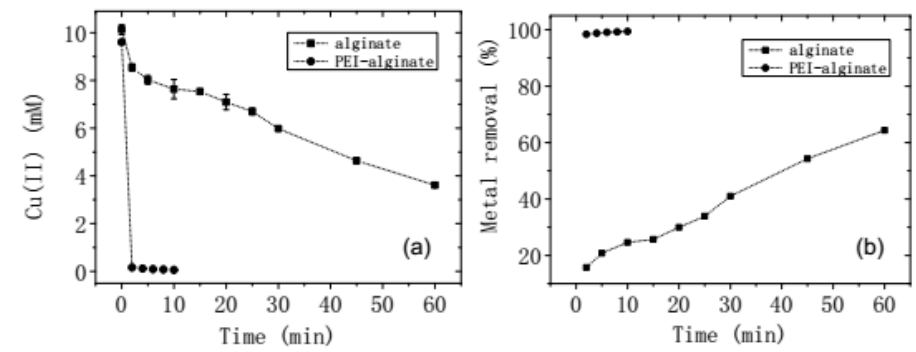

FIGURE 1. Removal of $\mathrm{Cu}(\mathrm{II})$. (a) Concentration of $\mathrm{Cu}(\mathrm{II})$ in solution; (b) removal percentage.

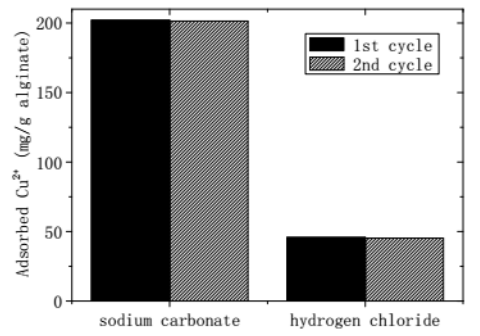

FIGURE 2. Reusability of the adsorbent after regeneration.

Hydrogen chloride regenerating process was rapid (Fig. 3) though the adsorption capacity was alleviated than $\mathrm{Na}_{2} \mathrm{CO}_{3}$ regenerated adsorbent. Compared to slow release of $\mathrm{Cu}(\mathrm{II})$ using the sodium carbonate, the released $\mathrm{Cu}(\mathrm{II})$ quickly approached $6.7 \mathrm{mM}$ within 5 min using hydrogen chloride, showing the potential of this process for enrichment of copper metal in a system as reported elsewhere [6]. The elution mechanism might involve the ionexchange of $\mathrm{Cu}(\mathrm{II})$ with $\mathrm{Na}^{+}$or $\mathrm{H}^{+}$[7]. From our experiments, the tightness of the complexes between the adsorbent and cations was in the order of $\mathrm{H}^{+}$-alginate $>\mathrm{Cu}(\mathrm{II})$-alginate $>\mathrm{Na}^{+}$-alginate. As a result, the adsorbent could be regenerated with $\mathrm{HCl}$ fast but the regenerated adsorbent had less capacity for $\mathrm{Cu}(\mathrm{II})$ adsorption.

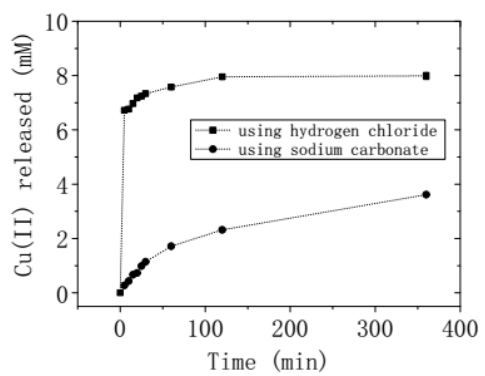

FIGURE 3. Desorption kinetics during regeneration.

\section{Adsorption of ferrous ion}

The capacity of this adsorbent for adsorption of other metal ion such as Fe(II) was also tested (Fig. 4). Similar to adsorption of $\mathrm{Cu}(\mathrm{II})$, the adsorption of $\mathrm{Fe}(\mathrm{II})$ was also rapid, reaching 95\% removal in just 2 min, broadening application of the adsorbent. Fe ions are discharged in a large amount by steel factory, copper etching solution, and 
paint industries, etc. They may be not only harmful to aquatic organisms [4] but also to human health. The fast adsorption kinetics made our adsorbent particularly useful for removal of $\mathrm{Fe}$ ions from concentrated waste water quickly.

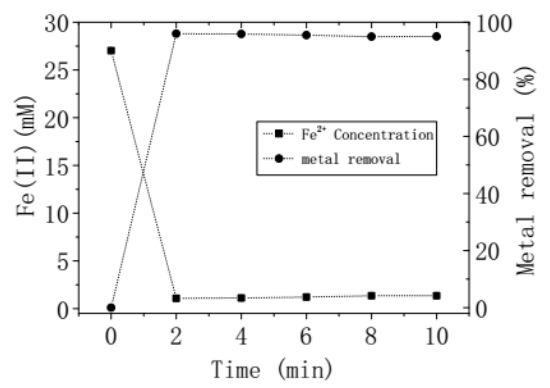

FIGURE 4. Adsorption of Fe(II).

\section{CONCLUSION}

A biological adsorbent was successfully developed by crosslinking alginate using PEI. Fast adsorption kinetics was obtained with $99.4 \%$ removal of $\mathrm{Cu}(\mathrm{II})$ within $10 \mathrm{~min}$ when the adsorbent was immersed in $10 \mathrm{mM} \mathrm{Cu}$ (II) solution. The adsorption capacity of $\mathrm{Cu}(\mathrm{II})$ reached $201 \mathrm{mg} / \mathrm{g}$ alginate. Surface characteristics of the adsorbent demonstrated a high content of $\mathrm{Cu}(\mathrm{II})(25.65 \mathrm{Wt} \%)$, confirming the high capacity for adsorption. Furthermore, the adsorbent also showed high capacity and fast removal of Fe(II), indicating potential of this biodegradable option for application in fast removal of different heavy metals.

\section{ACKNOWLEDGMENTS}

Corresponding author: Zhuoliang Ye. Email: yezl@fzu.edu.cn; ye_zhuoliang@163.com (Z. Ye). This work was financially supported by National Natural Science Foundation of China [grant number 21506037] and Fuzhou University Qishan Scholar [Oversea project, grant number XRC-1508].

\section{REFERENCES}

1. C. Jeon, Y. Je Yoo, W.H. Hoell, Environmental effects and desorption characteristics on heavy metal removal using carboxylated alginic acid, Bioresource Technology 96(1) (2005) 15-19.

2. X. Li, Y. Qi, Y. Li, Y. Zhang, X. He, Y. Wang, Novel magnetic beads based on sodium alginate gel crosslinked by zirconium(IV) and their effective removal for $\mathrm{Pb} 2+$ in aqueous solutions by using a batch and continuous systems, Bioresource Technology 142 (2013) 611-619.

3. C. Boschi, H. Maldonado, M. Ly, E. Guibal, Cd(II) biosorption using Lessonia kelps, Journal of Colloid and Interface Science 357(2) (2011) 487-496.

4. R.B. Sotero-Santos, O. Rocha, J. Povinelli, Toxicity of ferric chloride sludge to aquatic organisms, Chemosphere 68(4) (2007) 628-636.

5. W. Jung, B.-H. Jeon, D.-W. Cho, H.-S. Roh, Y. Cho, S.-J. Kim, D.S. Lee, Sorptive removal of heavy metals with nano-sized carbon immobilized alginate beads, Journal of Industrial and Engineering Chemistry 26 (2015) 364-369.

6. M. Mori, T. Suzuki, T. Sugita, D. Nagai, K. Hirayama, M. Onozato, H. Itabashi, Heavy metal adsorptivity of calcium-alginate-modified diethylenetriamine-silica gel and its application to a flow analytical system using flame atomic absorption spectrometry, Analytica Chimica Acta 840 (2014) 42-48.

7. G. Bayramoğlu, M. Yakup Arıca, Construction a hybrid biosorbent using Scenedesmus quadricauda and Caalginate for biosorption of $\mathrm{Cu}(\mathrm{II}), \mathrm{Zn}(\mathrm{II})$ and Ni(II): Kinetics and equilibrium studies, Bioresource Technology 100(1) (2009) 186-193. 